\title{
Upper airway cough syndrome may be the main cause of chronic cough in Japan: a cohort study
}

\section{Kimihiko Yasuda ( $\nabla$ kimihiko@yasuda-clinic.jp)}

\section{Research}

Keywords: aetiology of cough, chronic cough, post nasal drip syndrome, rhinosinusitis, sinusitis, upper airway cough syndrome

Posted Date: March 17th, 2020

DOI: https://doi.org/10.21203/rs.3.rs-17507/v1

License: (c) (i) This work is licensed under a Creative Commons Attribution 4.0 International License. Read Full License

Version of Record: A version of this preprint was published at Family Practice on June 11th, 2021. See the published version at https://doi.org/10.1093/fampra/cmab046. 


\section{Abstract}

Background: Upper airway cough syndrome (UACS) is generally considered the main cause of chronic cough, but it is rarely recognised in Japan. This study identified the causes of chronic cough and assessed whether "UACS is the most common cause of chronic cough" in Japan, as it is in other countries. Although signs and symptoms of UACS are described as nonspecific, some items of interviews and examinations might be considered potentially useful in its diagnosis, and were evaluated for their association with it.

Methods: All patients with chronic cough who visited my clinic were preliminarily diagnosed based on interviews and examinations. Bronchial asthma and UACS were preferentially diagnosed. Among the excluded cases, some patients with gastrointestinal symptoms or diet-related cough were diagnosed with gastroesophageal reflux disease, while others were diagnosed with post-infectious prolonged cough. Nasal corticosteroids were administered to the UACS group, and standard treatment to the other groups. The observation period lasted 4 weeks. Subjective cough score at first diagnosis was set at 10, and final diagnosis was made based on the treatment administered when the cough score had decreased to $\leq 2$. The association between the presence or absence of UACS and interview and examination items was statistically evaluated using a logistic regression model.

Results: Among 230 patients with chronic cough, 146 were diagnosed with UACS-only. In the UACS-only group treated with nasal corticosteroids, 110 patients showed a significant improvement in cough scores within 2 weeks. Multivariate logistic regression revealed that assessment items "awareness of mucus accumulating in the back of the throat" (odds ratio [OR]: 4.613; 95\% confidence interval [CI]: 1.124-18.928; $\mathrm{P}=0.034$ ), "presence of abnormal echography findings" (OR: 15.725; 95\% Cl: $1.445-171.101 ; \mathrm{P}=0.024)$, "absence of associated coughing when exercising" (OR: 0.212; 95\% Cl, 0.055-0.813; $\mathrm{P}=0.024$ ), and "presence of coughing persisting after onset" (OR: 6.470; 95\% $\mathrm{Cl}, 1.755-23.843 ; \mathrm{P}=0.005$ ) were significantly associated with the presence or absence of UACS.

Conclusions: UACS is the most common cause of chronic cough in Japan, as in other countries, and can be effectively treated with nasal corticosteroids. Diagnosing UACS might be possible by selecting appropriate interview and examination items.

\section{Background}

Cough is one of the most common complaints of patients visiting both respiratory and general medicine departments. When cough lasts for 8 weeks or longer, it is considered chronic [1-4]. In 1998, the American College of Chest Physicians (ACCP) stated that postnasal drip syndrome was the most common cause of chronic cough [5]. However, given that the cough associated with postnasal drip syndrome is not simply due to mechanical irritation caused by postnasal drip [6-8], it was termed upper airway cough syndrome (UACS) associated with rhinosinusitis in 2006. According to the ACCP, UACS is the most common cause of chronic cough, and treatments for UACS are recommended for chronic cough of unknown aetiology [1]. The European Respiratory Society (ERS) recommends using the brief term "rhinosinusitis" for UACS [2, 6, 7, 
9]. The diagnoses share the same status in terms of upper airway inflammation [9]. Furthermore, recently published ERS guidelines describe UACS as a cause of chronic cough [10].

Meanwhile, in the Japanese cough guidelines, cough variant asthma (CVA) is listed as the most common cause of chronic cough. Gastroesophageal reflux disease (GERD), sino-bronchial syndrome (SBS), and atopic cough (AC) are listed as other causes [3]. Few reports have shown that upper respiratory inflammation, such as UACS or rhinosinusitis, are the major causes of chronic cough in Japan. Niimi contested that racial differences may account for the low prevalence of UACS in Japan [11]. However, numerous studies on UACS have been reported from other Asian countries, and these reports indicate that UACS is a major cause of chronic cough in Asia. [12-19].

The aim here was to evaluate the prevalence of UACS in Japan by identifying the cause of chronic cough and to evaluate whether the ACCP statement that "UACS is the major cause of chronic cough" is valid in Japan. The ACCP also stated that "the symptoms and signs of UACS are nonspecific, and definitive diagnosis of UACS cannot be made from the medical history and physical examination alone" [20]. It was hypothesised that some interview and examination items associated with rhinosinusitis might be useful in UACS diagnosis. To evaluate this hypothesis, these items were compared between a UACS-only group and a group without UACS.

\section{Methods}

Patients with chronic cough who visited my clinic between March 2016 and July 2018 were included. Patients available for follow-up were prospectively treated, and the final diagnosis was evaluated (prospective analysis). The associations between interview and examinations items and UACS diagnosis was retrospectively examined (retrospective analysis).

\section{Interviews and examinations at the first visit}

Interviews (including questions in the questionnaire form shown in Table 1), pharynx and nasal cavity assessments, auscultation of the chest, chest radiography, pulmonary function tests, nasal discharge eosinophilic count, and maxillary sinus echography were performed at the first visit. The questionnaire was completed by the patients directly. All items in the list presented in Table 1 were checked. 
Table 1

Checklist used at the time of initial visit: characteristics, examination findings, and questionnaire items

\begin{tabular}{|c|c|c|}
\hline Characteristics & Assessment items & Standard \\
\hline Age & Age & Year(s) \\
\hline Sex & Male or female & $\mathrm{M} / \mathrm{F}$ \\
\hline History of smoking & $\begin{array}{l}\text { Has there ever been a history of smoking, including previous } \\
\text { smoking? }\end{array}$ & $\mathrm{Y} / \mathrm{N}$ \\
\hline History of asthma & Has there ever been a diagnosis of asthma? & $\mathrm{Y} / \mathrm{N}$ \\
\hline $\begin{array}{l}\text { Physical and laboratory } \\
\text { examination findings }\end{array}$ & Assessment items & Standard \\
\hline Auscultation & $\begin{array}{l}\text { Can wheezing, rhonchi, or squawking be heard on } \\
\text { auscultation? }\end{array}$ & $\mathrm{Y} / \mathrm{N}$ \\
\hline Pharyngeal examination & Are there findings of postnasal drip in the oropharynx? & $\mathrm{Y} / \mathrm{N}$ \\
\hline Nasal cavity observation & $\begin{array}{l}\text { Is there swelling or purulent nasal discharge in the middle or } \\
\text { lower turbinates as observed using a nasal speculum? }\end{array}$ & $\mathrm{Y} / \mathrm{N}$ \\
\hline Pulmonary function test & $\begin{array}{l}\text { Are there findings indicative of obstructive changes, such as } \\
\text { decreases in FEV1, \%FEV1, V50, and V } 25 \text { or a convex curve } \\
\text { below the FVC? }\end{array}$ & $\mathrm{Y} / \mathrm{N}$ \\
\hline Radiographic findings & Are there any findings that may cause coughing? & $\mathrm{Y} / \mathrm{N}$ \\
\hline $\begin{array}{l}\text { Maxillary sinus } \\
\text { echography }\end{array}$ & $\begin{array}{l}\text { Can the posterior wall bone be observed in the maxillary sinus } \\
\text { echography? }\end{array}$ & $\mathrm{Y} / \mathrm{N}$ \\
\hline $\begin{array}{l}\text { Assessment of } \\
\text { eosinophilic count in } \\
\text { nasal discharge }\end{array}$ & $\begin{array}{l}\text { Are there at least } 1+\text { eosinophils in nasal swab specimens } \\
\text { fixed onto glass slides? }\end{array}$ & $\mathrm{Y} / \mathrm{N}$ \\
\hline \multicolumn{3}{|c|}{ Items in the questionnaire form } \\
\hline $\begin{array}{l}\text { Regarding nasal } \\
\text { symptoms }\end{array}$ & Assessment items & Standard \\
\hline Awareness of runny nose & Is there awareness of runny nose? & $\mathrm{Y} / \mathrm{N}$ \\
\hline $\begin{array}{l}\text { Awareness of nasal } \\
\text { congestion }\end{array}$ & Is there awareness of nasal congestion? & $\mathrm{Y} / \mathrm{N}$ \\
\hline $\begin{array}{l}\text { Awareness of postnasal } \\
\text { drip }\end{array}$ & Is there awareness of postnasal drip? & $\mathrm{Y} / \mathrm{N}$ \\
\hline $\begin{array}{l}\text { History of nasal } \\
\text { symptoms }\end{array}$ & $\begin{array}{l}\text { If there are no nasal symptoms, was there awareness of } \\
\text { runny nose, nasal congestion, or postnasal drip prior to the } \\
\text { onset of coughing? }\end{array}$ & $\mathrm{Y} / \mathrm{N}$ \\
\hline Regarding coughing & Assessment items & Standard \\
\hline Duration of coughing & How many weeks has it been since you started coughing? & Week(s) \\
\hline
\end{tabular}


Characteristics

Coughing at night

Coughing at bedtime

Coughing at dawn

Choking coughing

Coughing that persists

after onset

Coughing after infection

Diet-related coughing

Coughing upon speaking

Coughing associated with atmospheric

changes

Coughing associated with changes in

temperature

Coughing upon

exercising

Coughing associated with warming of the body

\section{Regarding conditions} other than coughing

Presence of phlegm

Feeling of mucus accumulating in the back of the throat

Throat irritation

Dry throat

Difficulty in breathing

Wheezing

Clearing the throat

Hoarse throat
Assessment items

Standard

Does coughing occur at night?

$\mathrm{Y} / \mathrm{N}$

Does coughing occur at bedtime or when lying down?

$\mathrm{Y} / \mathrm{N}$

Does coughing occur at dawn?

$\mathrm{Y} / \mathrm{N}$

Does coughing feel like choking?

$\mathrm{Y} / \mathrm{N}$

Is there coughing that does not stop for a while after it

$\mathrm{Y} / \mathrm{N}$ begins?

Were there subjective symptoms of infection that triggered coughing (fever, cough, phlegm, runny nose, etc.)?

$\mathrm{Y} / \mathrm{N}$

Was coughing particularly frequent before and after or during $\quad \mathrm{Y} / \mathrm{N}$ meals?

Is coughing induced by speaking?

$\mathrm{Y} / \mathrm{N}$

Do atmospheric changes induce coughing?

$\mathrm{Y} / \mathrm{N}$

Do temperature differences (e.g. indoor to outdoor) induce coughing?

$\mathrm{Y} / \mathrm{N}$

Does exercise induce coughing?

$\mathrm{Y} / \mathrm{N}$

Does warming the body induce coughing?

$\mathrm{Y} / \mathrm{N}$

Assessment items

Standard

Is there awareness of phlegm?

$\mathrm{Y} / \mathrm{N}$

Is there awareness of the feeling of phlegm or mucus

$\mathrm{Y} / \mathrm{N}$

accumulating in the back of the throat?

Is there an irritating sensation in the throat?

$\mathrm{Y} / \mathrm{N}$

Does the throat feel dry?

$\mathrm{Y} / \mathrm{N}$

Is there any difficulty in breathing or a feeling of tightness in $\quad \mathrm{Y} / \mathrm{N}$ the anterior chest?

Is there awareness of wheezing?

$\mathrm{Y} / \mathrm{N}$

Is there awareness of throat clearing?

$\mathrm{Y} / \mathrm{N}$

Is there awareness of hoarse throat?

$\mathrm{Y} / \mathrm{N}$ 


\section{Characteristics}

Gastric symptoms
Assessment items

Standard

Is there awareness of gastric symptoms, such as acid reflux, epigastralgia, or nausea?
$\mathrm{Y} / \mathrm{N}$

FEV1, forced expiratory volume in 1 second; \%FEV1, percent predicted forced expiratory volume in 1 second; V50, flow rate at $50 \%$ forced vital capacity; V25, flow rate at $25 \%$ forced vital capacity; FVC, flow volume curve

\section{Diagnosis at the first visit}

I excluded patients who were under treatment that could cause coughing, such as with angiotensin converting enzyme inhibitors, or with abnormal shadows on chest radiography that could be indicative of conditions causing cough.

A preliminary diagnosis was made as shown in Fig. 1-A, B. First, the presence or absence of bronchial asthma (BA) was diagnosed based on the diagnostic criteria in accordance with the Global Initiative for Asthma [21]. Simultaneously, patients with symptoms of rhinosinusitis, such as postnasal drip, nasal discharge, and nasal congestion, or with abnormal findings on sinus echography (Fig. 2) were diagnosed with UACS. Patients who were not diagnosed with BA or UACS and had obvious gastric symptoms such as acid reflux, and a feeling of weight in the stomach or diet-related coughing were diagnosed with GERD. Patients who were not diagnosed with BA or UACS or GERD were diagnosed with post-infectious prolonged cough (PIPC). In view that CVA is a BA subtype, diagnosis of BA included both classical BA and CVA. Even if multiple diagnoses were possible, each patient was diagnosed with a single disease at the initial assessment to accurately evaluate the cause of the cough by clarifying the therapy effect of a single diagnosis. However, patients with both BA and UACS were diagnosed with combined conditions according to the concept of "one airway, one disease" [22].

\section{Treatments}

Treatment was initiated based on the preliminary diagnoses (Fig. 1-C).

Patients with BA received standard treatment according to the severity grade by combining inhaled corticosteroids, furancarboxylic acid fluticasone 100-200 $\mu \mathrm{g}$, and long-acting beta agonist, vilanterol $25 \mu \mathrm{g}$ once daily, and leukotriene receptor agonist, montelukast $10 \mathrm{mg}$ once daily.

Patients with UACS were treated with nasal corticosteroids, beclomethasone dipropionate $50 \mu \mathrm{g}$ twice daily or mometasone furoate $200 \mu \mathrm{g}$ once daily, oral carbocysteine 500 mg thrice daily; and herbal medicines, Kakkonto-ka-senkyu-shin-i or Shin-i-seihai-to $2.5 \mathrm{~g}$, thrice daily. Oral bepotastine $10 \mathrm{mg}$ twice daily was added only to patients with strong symptoms of allergic rhinitis including sneezing, nasal discharge, and nasal congestion, and pallor of the middle or lower turbinates observed with a nasal speculum. In patients whose cough score did not decrease to $\leq 2$ on first evaluation and whose eosinophilic count in nasal discharge was $\geq 1+$, nasal levocabastine was additionally administered at a dose of 0.2 mg; thrice daily 
and/or nasal corticosteroid administration was changed to several drops of betamethasone $(0.1 \%)$ twice daily as needed. Nasal betamethasone was not administered for longer than 2 weeks.

Famotidine $10 \mathrm{mg}$ or rabeprazole $10 \mathrm{mg}$ twice daily was administered to patients with GERD. Metoclopramide $5 \mathrm{mg}$ thrice daily and domperidone $10 \mathrm{mg}$ thrice daily were administered as needed.

Codeine phosphate $10 \mathrm{mg}$ and Bakumondo-to $3 \mathrm{~g}$, thrice daily were administered to patients with PIPC.

\section{Assessment of cough improvement}

The cough score in the initial diagnosis was set at 10; the degree of cough improvement was evaluated by the subjective cough score after the treatment. This assessment method has been shown to be highly correlated with the visual analogue scale score [23, 24].

\section{Evaluation and final diagnosis}

The observation period was set at 4 weeks. First evaluation was performed at 2 weeks after the start of treatment. Treatment was completed, continued, intensified, added, or changed based on the cough score (Fig. 1-D). The last evaluation was performed on week 4, final diagnosis was made based on the administered treatment at the time the cough score had decreased to $\leq 2$ (Fig. 1-E).

Patients who did not respond to any treatment and had a cough score $\geq 8$ were diagnosed with cough of unknown aetiology. In some patients who had reached a cough score $\leq 2$ prior to week 4 , treatment was completed early, and final diagnosis was made based on the administered treatment at that time. Patients with cough scores of 3-7 on week 4 were excluded because they were few $(n=4)$, these patients required continued treatment, and it was considered impossible to properly assess them within the pre-set 4-week follow-up period.

\section{Statistical analysis}

The group with a final diagnosis of UACS-only was compared with the group without UACS, and their differences in the items listed in Table 1 were evaluated. Median and 25th and 75th percentiles were obtained for continuous variables, and the Mann-Whitney $U$ test was used to determine significant differences between the groups. The degree and frequency of the variables were obtained, and Fisher's exact test was used to determine significant differences between the groups.

Predictive models were generated to determine whether the final diagnosis of UACS could be predicted by the interview and examination items. Univariate logistic regression models with the final diagnosis of UACS as the dependent variable and individual items as explanatory variables were generated. $A$ multivariate logistic regression model was generated by incorporating variables that achieved $p<0.1$ in the univariate analyses as the explanatory variables. Model selection based on Akaike's information criterion was performed using the variable-reduction method. To evaluate the discriminatory ability of the generated models, receiver operating characteristic analyses were performed, and the area under the curve was calculated. All statistical analyses were performed using R version 3.3.3 (R Core Team 2017 m, Vienna, Austria). $p<0.05$ was considered significant. 


\section{Results}

\section{Patient background}

Five hundred and seventy-six individuals with chronic cough visited our clinic between March 2016 and July 2018. One patient who was using an angiotensin converting enzyme inhibitor and three patients with radiographic findings that could have caused the chronic cough were excluded. Two hundred and thirty patients who visited regularly 2 or 4 weeks after their initial visit, so that their clinical course could be followed, were evaluated. Patients who did not return and whose clinical courses could not be followed were excluded. The mean patient age was $43.3 \pm 15.4$ years; 96 (41.7\%) were male, and 80 (34.8\%) were smokers (including previous smokers). The median duration of coughing was 12 weeks, the interquartile range was 16 weeks, and the range was $8-500$ weeks.

\section{Final diagnosis and breakdown of the number of patients in each disease group by the period to final diagnosis}

The final diagnosis in the 230 patients with chronic cough and the number of patients in each disease group broken down by the period until the cough score decreased to $\leq 2$ are shown in Fig. 3. Among the 230 patients, 146 (63.5\%) were classified in the UACS-only group, of whom 110 patients had achieved a cough score $\leq 2$ within 2 weeks.

\section{Characteristics of cough and absence/presence of nasal symptoms in the UACS-only group}

Of the 146 patients diagnosed with UACS-only, 108 (74.0\%) had productive and $38(26.0 \%)$ had nonproductive cough. Of the 108 patients with productive cough, 81 exhibited nasal symptoms, including postnasal drip. Of the 38 patients with non-productive cough, 24 exhibited nasal symptoms, including postnasal drip (Table 2).

Table 2

Characteristics of cough and absence/presence of nasal symptomsin the UACS-only group

\begin{tabular}{|lll|}
\hline & Wet cough $(\mathbf{N}=108)$ & Dry cough $(\mathbf{N}=\mathbf{3 8})$ \\
\hline $\begin{array}{l}\text { Non-silent UACS: nasal symptom }(+) \\
(\mathrm{N}=105)\end{array}$ & 81 & 24 \\
\hline $\begin{array}{l}\text { Silent UACS: nasal symptom }(-) \\
(\mathrm{N}=41)\end{array}$ & 27 & 14 \\
\hline UACS, upper airway cough syndrome & & \\
\hline
\end{tabular}

\section{Statistical analyses results}


Interview and examination items shown in Table 1 were compared between the group with a final diagnosis of UACS-only $(n=146)$ and the group without UACS $(n=18$ : GERD, 4; PIPC, 3; GERD + PIPC, 1 ; BA, 1 ; unknown, 9). A significant difference, $(p<0.05)$ was observed in the seven items listed in Table 3.

Table 3

Comparison of patient characteristics in the UACS-only group and without UACS group

\begin{tabular}{|llll|}
\hline & $\begin{array}{l}\text { UACS-only }(\mathbf{N}= \\
\text { 146) }\end{array}$ & $\begin{array}{l}\text { Without UACS (N } \\
\mathbf{2 1 8}\end{array}$ & $\begin{array}{l}\text { P- } \\
\text { value }\end{array}$ \\
\hline Swelling of the middle and lower turbinates (Yes) & $92(63.0 \%)$ & $6(33.3 \%)$ & $0.021^{*}$ \\
\hline Runny nose (Yes) & $70(47.9 \%)$ & $3(16.7 \%)$ & $0.012^{*}$ \\
\hline Existence of a possible trigger for infection (Yes) & $86(58.9 \%)$ & $4(22.2 \%)$ & $0.005^{*}$ \\
\hline Awareness of postnasal drip (Yes) & $43(29.5 \%)$ & $1(5.6 \%)$ & $0.045^{*}$ \\
\hline $\begin{array}{l}\text { Presence of abnormal maxillary sinus echography } \\
\text { findings (Yes) }\end{array}$ & $144(98.6 \%)$ & $15(83.3 \%)$ & $0.010^{*}$ \\
\hline $\begin{array}{l}\text { Cough that persists after onset (Yes) } \\
\text { Awareness of wheezing (Yes) }\end{array}$ & $99(67.8 \%)$ & $7(38.9 \%)$ & $0.020^{*}$ \\
\hline$* P<0.05$ UACS, upper airway cough syndrome & $13(8.9 \%)$ & $5(27.8 \%)$ & $0.031^{*}$ \\
\hline
\end{tabular}

Ten items with $p<0.1$ in the univariate analysis are shown in Table 4. 
Table 4

Items with $\mathrm{P}<0.1$ in univariate logistic regression analysis (with presence/absence of UACS as objective variable)

\begin{tabular}{|lllll|}
\hline & $\begin{array}{l}\text { Odds } \\
\text { ratio }\end{array}$ & $\begin{array}{l}95 \% \\
\text { lower } \\
\text { limit }\end{array}$ & $\begin{array}{l}\text { upper } \\
\text { limit }\end{array}$ & value \\
\hline Duration of coughing (weeks) & 0.995 & 0.990 & 1.001 & 0.082 \\
\hline Existence of a possible trigger of infection $(\mathrm{Y} / \mathrm{N})$ & 5.017 & 1.704 & 18.372 & $0.006^{*}$ \\
\hline Runny nose $(\mathrm{Y} / \mathrm{N})$ & 4.605 & 1.445 & 20.489 & $0.019^{*}$ \\
\hline Awareness of the presence of postnasal drip $(\mathrm{Y} / \mathrm{N})$ & 7.097 & 1.389 & 129.869 & 0.060 \\
\hline $\begin{array}{l}\text { Awareness of the presence of sputum from the nose that } \\
\text { accumulated at the back of the throat }(\mathrm{Y} / \mathrm{N})\end{array}$ & 5.963 & 2.022 & 21.871 & $0.002^{*}$ \\
\hline Findings of middle and lower turbinate swelling $(\mathrm{Y} / \mathrm{N})$ & 3.407 & 1.248 & 10.274 & $0.020^{*}$ \\
\hline Coughing upon exercise $(\mathrm{Y} / \mathrm{N})$ & 0.406 & 0.147 & 1.186 & 0.086 \\
\hline Cough that does not stop after onset $(\mathrm{Y} / \mathrm{N})$ & 3.31 & 1.226 & 9.511 & $0.020^{*}$ \\
\hline Awareness of the presence of wheezing $(\mathrm{Y} / \mathrm{N})$ & 0.254 & 0.081 & 0.89 & $0.022^{*}$ \\
\hline $\begin{array}{l}\text { Presence of abnormal findings on maxillary echography } \\
\text { (Y/N) }\end{array}$ & 14.4 & 2.224 & 116.126 & $0.005^{*}$ \\
\hline$* \mathrm{P}<0.05$ UACS, upper airway cough syndrome & & & & \\
\hline
\end{tabular}

A full model incorporating these 10 items was generated, and selection of variables using the variablereduction method based on Akaike's information criterion was performed. After reconstructing the model, a significant association with the presence or absence of UACS $(p<0.05)$ was found with the following assessment items: "awareness of mucus accumulating in the back of the throat"(odds ratio [OR]: 4.613; 95\% confidence interval [Cl], 1.124-18.928; P-value $=0.034)$, "presence of abnormal echography findings" (OR: $15.725 ; 95 \% \mathrm{Cl}, 1.445-171.101 ; \mathrm{P}$-value $=0.024$ ), "absence of associated coughing when exercising" (OR: $0.212 ; 95 \% \mathrm{Cl}, 0.055-0.813 ; \mathrm{P}-\mathrm{value}=0.024$ ), and "presence of coughing persisting after onset" (OR: $6.470 ; 95 \% \mathrm{Cl}, 1.755-23.843 ;$ P-value $=0.005)($ Table 5$)$. 
Table 5

Results of multivariate analysis using a binomial logistic regression model: after backward stepwise model selection

\begin{tabular}{|lllll|}
\hline & $\begin{array}{l}\text { Odds } \\
\text { ratio }\end{array}$ & $\begin{array}{l}95 \% \text { Cl lower } \\
\text { limit }\end{array}$ & $\begin{array}{l}95 \% \text { Cl upper } \\
\text { limit }\end{array}$ & $\begin{array}{l}\text { P- } \\
\text { value }\end{array}$ \\
\hline Existence of a possible trigger for infection $(\mathrm{Y} / \mathrm{N})$ & 4.011 & 0.984 & 16.355 & 0.052 \\
\hline $\begin{array}{l}\text { Awareness of mucus accumulating in the back } \\
\text { of the throat }(\mathrm{Y} / \mathrm{N})\end{array}$ & 4.613 & 1.124 & 18.928 & $0.034^{*}$ \\
\hline $\begin{array}{l}\text { Presence of abnormal maxillary sinus } \\
\text { echography findings }(\mathrm{Y} / \mathrm{N})\end{array}$ & 15.725 & 1.445 & 171.101 & $0.024^{*}$ \\
\hline $\begin{array}{l}\text { Coughing upon exercise }(\mathrm{Y} / \mathrm{N}) \\
\text { Cough that persists after onset }(\mathrm{Y} / \mathrm{N})\end{array}$ & 0.212 & 0.055 & 0.813 & $0.024^{*}$ \\
\hline Awareness of postnasal drip $(\mathrm{Y} / \mathrm{N})$ & 6.47 & 1.755 & 23.843 & $0.005^{*}$ \\
\hline Swelling of the middle and lower turbinates $(\mathrm{Y} / \mathrm{N})$ & 2.543 & 0.712 & 9.088 & 0.206 \\
\hline *P<0.05; Cl, confidence interval; UACS, upper airway cough syndrome & & 0.151 \\
\hline
\end{tabular}

Receiver operating characteristics analyses were performed to evaluate the discriminatory ability of the multivariate model, and the area under curve was 0.863 . The sensitivity was $72.60 \%$, the specificity was $94.44 \%$, the positive predictive value was $99.07 \%$, and the negative predictive value was $29.82 \%$.

\section{Discussion}

UACS is widely recognized as a cause of chronic cough. However, its prevalence is considered low in Japan $[3,11]$. As it is unlikely that Japan constitutes the only exception, this study was conducted to examine the actual UACS prevalence in Japan. In this study, UACS was the most common cause of chronic cough. It was effectively treated by nasal corticosteroids. Some interview and examination items were useful for UACS diagnosis.

According to the ACCP guidelines, antihistamines/decongestants are recommended for UACS treatment, and the diagnosis should be based on the response to antihistamines in addition to symptoms and examinations [1]. The concept of "silent UACS" without nasal symptoms, diagnosed only by the efficacy of antihistamine treatment was also presented [20,25]. First-generation antihistamines are recommended for UACS treatment [1]. The mechanism of action is considered to be mainly anticholinergic (suppression of cholinergic vagal reflex); the binding affinity of histamine receptors may not be highly correlated, but no definite conclusion has been reached [26]. This medicine may have strong sedative-hypnotic side effects, which can cause antitussive activity [6]. Therefore, instead of first-generation antihistamines, nasal corticosteroids were administered, as recommended by the European and American guidelines for rhinosinusitis, in this study [27-32]. Because UACS and rhinosinusitis share the same pathophysiological 
status, treatment with nasal corticosteroids for UACS is appropriate and has been previously reported [33, 34]. In this study, in 110 (75.3\%) of the 146 patients with a final UACS-only diagnosis, cough scores significantly improved (from 10 to $\leq 2$ ) within only 2 weeks with nasal corticosteroid administration. Although ERS cough guidelines state that there is no evidence of localised treatment being effective against UACS [10], this finding indicates that inflammation in the nasal cavity plays a central role in the pathophysiology of UACS. Compared with antihistamines, nasal corticosteroids constitute a potent therapeutic option for UACS in terms of efficacy, side effects, and clarification of the location of the primary pathophysiology. The efficacy and mechanism of action of herbal medicines used for treating rhinosinusitis have been demonstrated in Japan, China, and Korea [35-42].

UACS is described only briefly in the Japanese cough guideline [3] and is poorly recognised [11]. It would be interesting to examine why this is the case. The Japanese Cough Guidelines state that CVA, SBS, AC, and GERD are the major causes of chronic cough [3]. SBS, which is defined as chronic recurrent neutrophilic inflammation of the upper and lower airways, is described as a cause of chronic cough only in the Japanese guidelines. Macrolides are effective in treating SBS, and the therapeutic effect is determined based on improvements within 4-8 weeks after administration [3]. Although the concept of SBS differs from that of UACS in that it defines the presence of lower-airway as well as upper-airway lesions (rhinosinusitis), its clinical status largely overlaps with that of UACS [25]. In other words, rhinosinusitis as a cause of chronic cough has been incorporated into the SBS concept and is not recognized as a separate causative disease in Japan. AC had been reported mostly from Japan [43-45]. The condition has been defined as dry cough that can be effectively treated with inhaled corticosteroids or antihistamines and is characterised by eosinophilic central airway inflammation $[3,43,44]$. The concept of AC pathophysiologically overlaps with those of CVA and non-asthmatic eosinophilic bronchitis, and whether $A C$ is an independent disease remains controversial $[2,11,25,46]$. Niimi and Yu noted that $A C$ may overlap with silent UACS, which is not associated with nasal symptoms and the associated cough symptoms can be improved in this case with antihistamine administration [11, 25]. Additionally, UACS associated with allergic rhinitis that can be ameliorated by antihistamines may overlap with AC. As these diseases overlapping with UACS are recognized as causes of chronic cough, UACS may not be recognized as a cause in itself in Japan.

ACCP reported that "the symptoms and signs of UACS are nonspecific, definitive diagnosis cannot be made from the medical history and physical examination alone" [1]. Several interview and examination items associated with rhinosinusitis were useful in diagnosing UACS in this study. The questions shown in Table 1 refer to common cough-related patient complaints and the major rhinosinusitis guidelines in the United States and Europe [27-32]. These guidelines utilise both clinical symptoms and objective findings for rhinosinusitis diagnosis. Given that UACS shares the same status with rhinosinusitis, it is reasonable to refer to the features of rhinosinusitis for the diagnosis of UACS. All guidelines recommend computed tomography, but echography might be a useful diagnostic tool, as it is economical, convenient, and does not involve radiation exposure [47-49]. 
More than half of patients presenting with chronic cough were excluded because they did not revisit the clinic for various reasons, and their clinical course could not be followed up. Many of them did not visit the clinic because their symptoms improved. On the other hand, some patients may not have been able to visit the clinic because their symptoms did not improve. There are no data on the extent and duration of cough improvement in these cases. Nevertheless, patients who did not return should have been followed up over the phone or by other means. More patients were diagnosed with UACS than with BA in this study. In general, outpatients often consult a physician before their cough becomes chronic. CVA is generally recognised among general practitioners because the Japanese guidelines specify CVA as the major cause of chronic cough [3]. Therefore, in many cases, inhaled corticosteroids had been empirically administered before the patients visited my clinic (data not shown). Thus, the possibly high number of cases that had not improved with inhaled corticosteroid use may have inflated the prevalence UACS over CVA as a cause of chronic cough. In addition, most patients with BA presented with nasal symptoms or abnormal echography findings and received UACS treatment. Although some patients should have been diagnosed with BA only, they may have been over-diagnosed with complicated UACS. The diagnosis of BA and UACS should have been separated. However, even when all these patients were diagnosed with BA only, the prevalence of UACS in patients with chronic cough was 63.5\%. This result indicates that UACS remained the most common cause of chronic cough. The large difference in the number of patients with UACS-only and those without UACS may have biased the statistical results regarding the diagnostic items. This bias may be avoided by equalising the number of patients. This correction may lead to more accurate identification of diagnostic items for UACS. The interview and examination items were limited, and there might be additional items that could be useful for diagnosis. In this study, nine patients were diagnosed with cough of unknown aetiology. In 2016, a systematic review of randomized controlled trials of unexplained chronic cough showed that gabapentin was the only recommended treatment [50]; hence, gabapentin should have been considered to treat cough of unknown aetiology in this study.

\section{Conclusions}

"UACS is the most common cause of chronic cough," as stated by the ACCP, appears to also apply to the Japanese population based on our findings, and it can be effectively treated with nasal corticosteroids. Some interview and examination items may be able to increase the diagnostic accuracy of UACS.

\section{Abbreviations}

AC

atopic cough

ACCP

American College of Chest Physicians

BA

bronchial asthma

$\mathrm{Cl}$

confidence interval; 
CVA

cough variant asthma

ERS

European Respiratory Society

GERD

gastroesophageal reflux disease

OR

odds ratio

PIPC

post-infectious prolonged cough

SBS

sino-bronchial syndrome

UACS

upper airway cough syndrome

\section{Declarations}

\section{Ethics approval and consent to participate and consent for publication}

This clinical study was performed in accordance with the Declaration of Helsinki, with the approval of the institution's ethics review board (\#15-06-01). Informed consent was not required because, instead of obtaining direct consent from patients, Information such as research purposes, methods, and handling of personal information was posted in the clinic and on the website. Participants were provided with the optout opportunity to refuse or drop out of the study. I ensured that patient anonymity was respected by removing any detail that may have led to patient identification.

\section{Availability of data and materials}

The data that support the findings of this study are available from the corresponding author upon reasonable request.

\section{Funding}

This study is not funded by a specific project grant.

\section{Competing interests}

The author declare that I have no competing interests.

\section{Author information}

Affiliations: Not applicable

Contributions: Not applicable 
Corresponding author: Not applicable

\section{Acknowledgements}

I would like to show my greatest appreciation to Yoshiaki Tanaka M.D. and Masako Yasuda M.D. whose comments and suggestions were innumerably valuable throughout the course of my study. I would like to extend my appreciation to the staff at the clinic who helped me organise the data.

\section{References}

1. Irwin RS, Baumann MH, Bolser DC, Boulet LP, Braman SS, Brightling CE, et al. Diagnosis and management of cough executive summary: ACCP evidence-based clinical practice guidelines. Chest. 2006; 129:1S-23S.

2. Morice AH, McGarvey L, Pavord I; British Thoracic Society Cough Guideline Group. Recommendations for the management of cough in adults. Thorax. 2006; 61 Suppl 1:i1-24.

3. Committee for the Japanese Respiratory Society Guidelines for Management of Cough, Kohno S, Ishida T, Uchida Y, Kishimoto H, Sasaki H, et al. The Japanese Respiratory Society guidelines for management of cough. Respirology. 2006; 11 Suppl 4:S135-86.

4. Irwin RS, French CL, Chang AB, Altman KW; CHEST Expert Cough Panel. Classification of cough as a symptom in adults and management algorithms: CHEST Guideline and Expert Panel Report. Chest. 2018; 153:196-209.

5. Irwin RS, Boulet LP, Cloutier MM, Fuller R, Gold PM, Hoffstein V, et al. Managing cough as a defense mechanism and as a symptom: a consensus panel report of the American College of Chest Physicians. Chest. 1998; 114:133S-81S.

6. Morice AH. Post-nasal drip syndrome-a symptom to be sniffed at? Pulm Pharmacol Ther. 2004; 17:343-5.

7. O'Hara J, Jones NS. "Post-nasal drip syndrome": most patients with purulent nasal secretions do not complain of chronic cough. Rhinology. 2006; 44:270-3.

8. Bardin PG, Van Heerden BB, Joubert JR. Absence of pulmonary aspiration of sinus contents in patients with asthma and sinusitis. J Allergy Clin Immunol. 1990; 86:82-8.

9. Sanu A, Eccles R. Postnasal drip syndrome. Two hundred years of controversy between UK and USA. Rhinology. 2008; 46:86-91.

10. Morice AH, Millqvist E, Bieksiene K, Birring SS, Dicpinigaitis P, Domingo Ribas C, et al. ERS guidelines on the diagnosis and treatment of chronic cough in adults and children. Eur Respir J. 2020; 55:1901136.

11. Niimi A. Geography and cough aetiology. Pulm Pharmacol Ther. 2007; 20:383-7.

12. Lai K, Chen R, Lin J, Huang K, Shen $H$, Kong L, et al. A prospective, multicenter survey on causes of chronic cough in China. Chest. 2013; 143:613-20. 
13. Rhee CK, Jung JY, Lee SW, Kim JH, Park SY, Yoo KH, et al. The Korean Cough Guideline: Recommendation and Summary Statement. Tuberc Respir Dis (Seoul). 2016; 79:14-21.

14. Mahashur A. Chronic dry cough: diagnostic and management approaches. Lung India. 2015; 32:44-9.

15. Lai K. Chinese National Guidelines on Diagnosis and Management of Cough: consensus and controversy. J Thorac Dis. 2014; 6:S683-8.

16. Nantha YS. Therapeutic-diagnostic evaluation of chronic cough amongst adults: causes, symptoms and management at the primary care level, Malaysia. J Family Med Prim Care. 2014; 3:207-12.

17. Gao F, Gu QL, Jiang ZD. Upper airway cough syndrome in 103 children. Chin Med J (Engl). 2019; 132:653-8.

18. Ding H, Xu X, Wen S, Yu Y, Pan J, Shi C, et al. Changing etiological frequency of chronic cough in a tertiary hospital in Shanghai, China. J Thorac Dis. 2019; 11:3482-9.

19. Koo HK, Jeong I, Lee SW, Park J, Kim JH, Park SY, et al. Prevalence of chronic cough and possible causes in the general population based on the Korean National Health and Nutrition Examination Survey. Medicine (Baltimore). 2016; 9:e4595.

20. Pratter MR. Chronic upper airway cough syndrome secondary to rhinosinus diseases (previously referred to as postnasal drip syndrome): ACCP evidence-based clinical practice guidelines. Chest. 2006; 129:63S-71S.

21. Global Initiative for Asthma. Global Strategy for asthma management and prevention - Update 2019. www.ginasthma.com. Accessed 18 Feb 2020.

22. Grossman J. One airway, one disease. Chest. 1997; 111:11S-6S.

23. Nobata K, Asanoi H. Proton pump inhibitor-responsive chronic cough without acid reflux: a case report. J Med Case Rep. 2007; 1:69.

24. Ota K. The study of the evaluation methods to the severity of persistent cough. Allergology \& Immunology. 2008; 15:132-41. [in Japanese]

25. Yu L, Xu X, Lv H, Qiu Z. Advances in upper airway cough syndrome. Kaohsiung J Med Sci. 2015; 31:223-8.

26. Bolser DC. Older-generation antihistamines and cough due to upper airway cough syndrome (UACS): efficacy and mechanism. Lung. 2008; 186 Suppl 1:S74-7.

27. Meltzer EO, Hamilos DL. Rhinosinusitis diagnosis and management for the clinician: a synopsis of recent consensus guidelines. Mayo Clin Proc. 2011; 86:427-43.

28. Fokkens W, Lund V, Mullol J; European Position Paper on Rhinosinusitis and Nasal Polyps Group. European position paper on rhinosinusitis and nasal polyps 2007. Rhinology Suppl. 2007; 20:1-136.

29. Scadding GK, Durham SR, Mirakian R, Jones NS, Drake-Lee AB, Ryan D, et al. BSACl guidelines for the management of rhinosinusitis and nasal polyposis. Clin Exp Allergy. 2008; 38:260-75.

30. Slavin RG, Spector SL, Bernstein IL, Kaliner MA, Kennedy DW, Virant FS, et al. The diagnosis and management of sinusitis: a practice parameter update. J Allergy Clin Immunol. 2005; 116:S13-47. 
31. Rosenfeld RM, Piccirillo JF, Chandrasekhar SS, Brook I, Ashok Kumar K, Kramper M, et al. Clinical practice guideline (update): adult sinusitis. Otolaryngol Head Neck Surg. 2015; 152:S1-39.

32. Meltzer EO, Hamilos DL, Hadley JA, Lanza DC, Marple BF, Nicklas RA, et al. Rhinosinusitis: establishing definitions for clinical research and patient care. J Allergy Clin Immunol. 2004; 114:155-212.

33. Macedo P, Saleh H, Torrego A, Arbery J, MacKay I, Durham SR, et al. Postnasal drip and chronic cough: an open interventional study. Respir Med. 2009; 103:1700-5.

34. Asilsoy S, Bayram E, Agin H, Apa H, Can D, Gulle S, et al. Evaluation of chronic cough in children. Chest. 2008; 134:1122-8.

35. Ito H, Suzuki Y, Fukuoka Y, Hamada K. Effect of the Chinese drug "Kakkontoka Senkyushini" against chronic sinusitis in children. Practica Otologica. 1995; 77:1479-81. [in Japanese]

36. Kato S. Effects of erythromycin combined with Kakkon-to-ka-senkyu-shinn'l against chronic lower respiratory infection of the inflammatory sinusitis. Kampo and Immuno-allergy. 1998; 12:140-9. [in Japanese]

37. Kimura M, Kimura I, Guo X, Luo B, Kobayashi S. Combined effects of Japanese-Sino medicine 'Kakkon-to-ka-senkyu-shin'i' and its related combinations and component drugs on adjuvant-induced inflammation in mice. Phytother Res. 1992; 6:209-16.

38. Yamagiwa M. The immediate effect of Kakkon-to-ka-senkyu-shin'i (Ge-gen-tang-jia-chuan-xiong-xin-yi) on nasal obstruction evaluated by acoustic rhinometry. Kampo Med. 1995; 46:83-9. [in Japanese]

39. Minami M, Konishi T, Takase H, Makino T. Shin'iseihaito (xinyiqingfeitang) suppresses the biofilm formation of Streptococcus pneumoniae in vitro. Biomed Res Int. 2017; doi:10.1155/2017/4575709.

40. Minami M, Konishi T, Jiang Z, Arai T, Makino T. Effect of Shin'iseihaito on murine allergic reaction induced by nasal sensitization. J Tradit Complement Med. 2016; 6:252-6.

41. Matsunaga S, Itoh K, Babazono M, Imamura Y, Ohyama M. Effects of Shin'i-seihai-to and Sho-seiryu-to on production of active oxygen species by neutrophils. Pract Otorhinolaryngol. 1992; 85:1975-80.

42. Okamura Y, Takano S, Aramaki H. Kampo therapy to treat intractable chronic sinusitis patients. Pract Otorhinolaryngol. 1997; 92:47-50. [in Japanese]

43. Fujimura M, Abo M, Ogawa H, Nishi K, Kibe Y, Hirose T, et al. Importance of atopic cough, cough variant asthma and sinobronchial syndrome as causes of chronic cough in the Hokuriku area of Japan. Respirology. 2005; 10:201-7.

44. Fujimura M, Ogawa H, Nishizawa Y, and Nishi K. Comparison of atopic cough with cough variant asthma: is atopic cough a precursor of asthma? Thorax. 2003; 58:14-8.

45. Kita T, Fujimura M, Ogawa H, Nakatsumi Y, Nomura S, Ishiura Y, et al. Antitussive effects of the leukotriene receptor antagonist montelukast in patients with cough variant asthma and atopic cough. Allergol Int. 2010; 59:185-92.

46. McGarvey L, Morice AH. Atopic cough: little evidence to support a new clinical entity. Thorax. 2003; 58:736-8.

47. Haapaniemi J, Laurikainen E. Ultrasound and antral lavage in the examination of maxillary sinuses. Rhinology. 2001; 39:39-42. 
48. Savolainen S, Pietola M, Kiukaanniemi H, Lappalainen E, Salminen M, Mikkonen P. An ultrasound device in the diagnosis of acute maxillary sinusitis. Acta Otolaryngol Suppl. 1997; 529:148-52.

49. Varonen H, Mäkelä M, Savolainen S, Läärä E, Hilden J. Comparison of ultrasound, radiography, and clinical examination in the diagnosis of acute maxillary sinusitis: a systematic review. J Clin Epidemiol. 2000; 53:940-8.

50. Gibson P, Wang G, McGarvey L, Vertigan AE, Altman KW, Birring SS, et al. Treatment of unexplained chronic cough: CHEST Guideline and Expert Panel Report. Chest. 2016; 149:27-44.

\section{Supplementary Information}

Additional file 1. Table S1: Comparison of all items of interviews and examinations between the UACS-only group and without UACS group. Table S2: Univariate logistic regression analyses using the presence or absence of UACS as an objective variable. Table S3: Results of multivariate analysis using a binomial logistic regression model to determine whether UACS is present or not. Table S4: Discriminant performance evaluation results of the final built model; discrimination result. Figure S1: Discriminant performance evaluation results of the built model: ROC curve

\section{Figures}

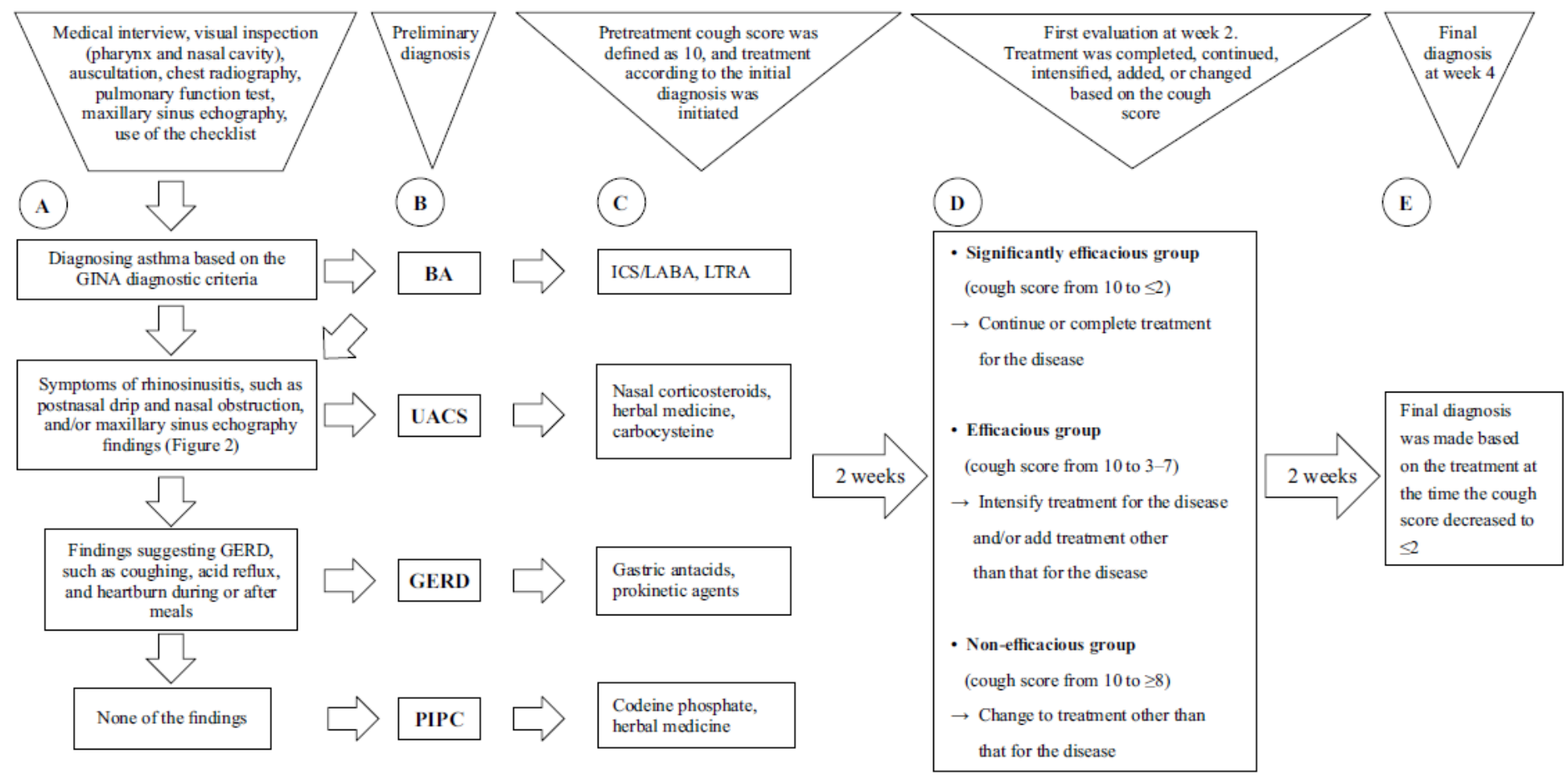

\section{Figure 1}

Flow chart of diagnosis and treatment. GINA, global initiative for asthma; BA, bronchial asthma; UACS, upper airway cough syndrome; GERD, gastroesophageal reflux disease; PIPC, post infectious prolonged cough; ICS, inhaled corticosteroids; LABA, long-acting beta agonist; LTRA, leukotriene receptor agonist; 


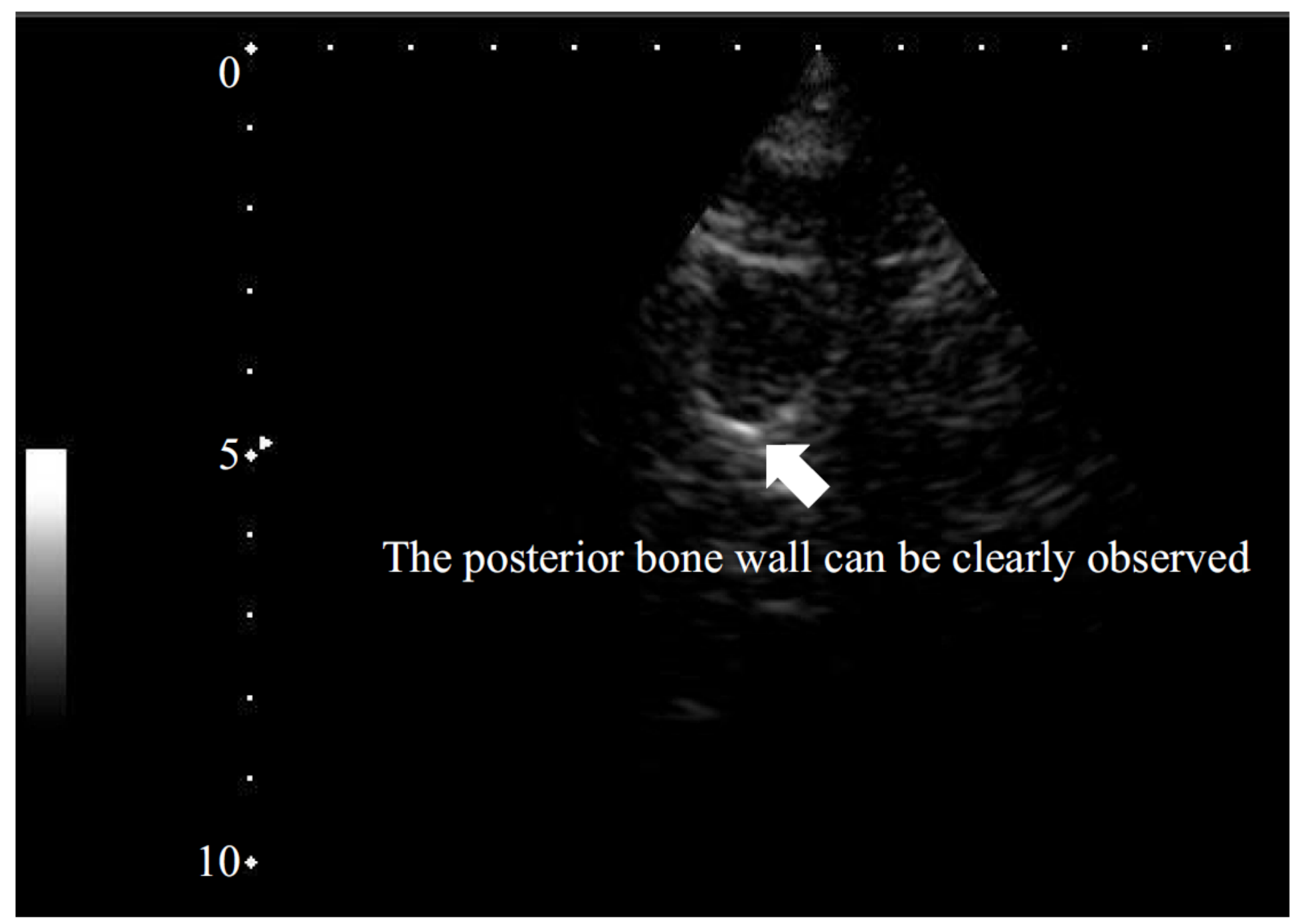

\section{Figure 2}

Abnormal maxillary sinus echography. The sector probe was moved vertically to the horizontal line of the maxillary sinus to confirm whether the posterior wall bone could be observed. The posterior wall bone is usually not visible. 


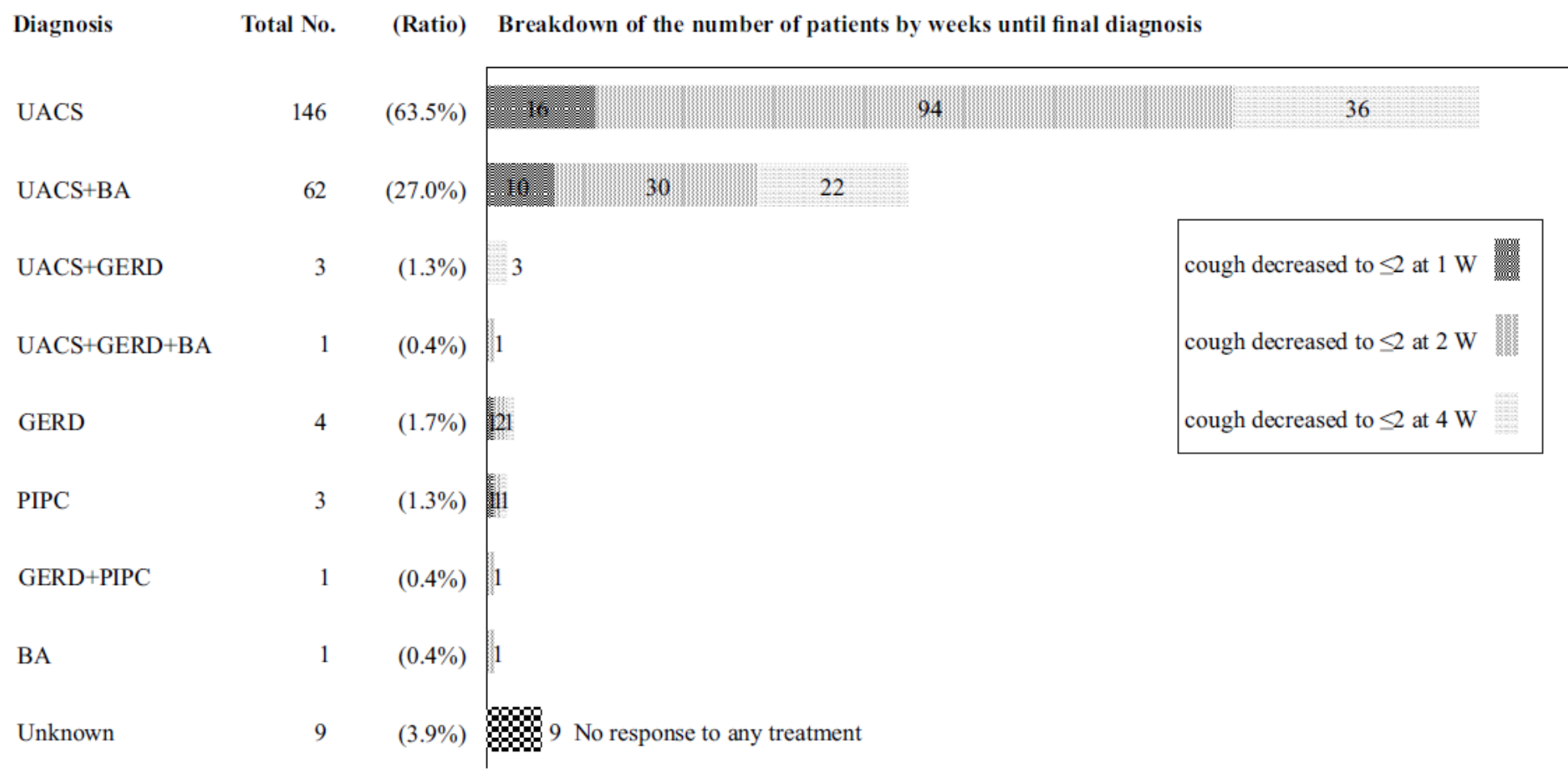

\section{Figure 3}

Diagnosis and breakdown of patient number in each disease group by period till final diagnosis. UACS, upper airway cough syndrome; BA, bronchial asthma; GERD, gastrooesophageal reflux disease; PIPC, post infectious prolonged cough

\section{Supplementary Files}

This is a list of supplementary files associated with this preprint. Click to download.

- KimihikoYasudaAdditionalfile1.docx 